\title{
The production of high purity alumina from solid wastes obtained from aluminium factories
}

\author{
M. G. Ghoniem ${ }^{1}$, T. M. Sami ${ }^{2}$, S. A. El-Reefy ${ }^{3}$ \& S. A. Mohamed ${ }^{4}$ \\ ${ }^{1}$ Chemistry Department, \\ Al-Imam Muhammad Ibn Saud Islamic University, Saudi Arabia \\ ${ }^{2}$ Tabbin Institute for Metallurgical Studies, Egypt \\ ${ }^{3}$ Hot Laboratories Center, Atomic Energy Authority, Egypt \\ ${ }^{4}$ Faculty of Science, Ain Shams University, Egypt
}

\begin{abstract}
This work is directed to the production of alumina $\left(\mathrm{Al}_{2} \mathrm{O}_{3}\right)$, from the solid waste cake produced as a by-product from some aluminium small factories. Aluminium ions in this cake are separated as sodium aluminate solution $\left(\mathrm{NaAlO}_{2}\right)$, as a result of treating the solid cake with commercial caustic soda solution. Aluminium hydroxide is precipitated from $\mathrm{NaAlO}_{2}$ solution by purging $\mathrm{CO}_{2}$ gas through the hot solution. The resulting precipitate is separated by filtration, washed with hot water, dried at $105^{\circ} \mathrm{C}$, then calcined at 600 or $1000^{\circ} \mathrm{C}$ to produce pure alumina of $\gamma$ - or $\alpha$-form, respectively.

Keywords: alumina, sodium aluminates, aluminum hydroxide, leaching, solid waste.
\end{abstract}

\section{Introduction}

Small factories producing aluminum utensils, after shaping, use sodium hydroxide baths for glazing the surface of the product. The spent bath always contains a solid waste cake which contains more than $80 \%$ of aluminum compounds mainly as hydroxides and aluminates. This solid waste is generally dried by solar energy and disposed in landfill with remarkable amounts which represents an environmental problem. This solid waste can be recycled and aluminum compounds in pure state can be recovered after a leaching process. These aluminum compounds are of high economic value and have wide applications. 
The aim of the present study is to recover aluminium ions from the solid waste produced from some Egyptian small factories producing aluminum utensils. Production of alumina $\left(\mathrm{Al}_{2} \mathrm{O}_{3}\right)$ is the main goal of such study.

Recovery of aluminum from both liquid and solid wastes has been reported by different authors. Rayzman et al. [1] produced sodium aluminate solution from alumina-bearing intermediates and wastes including spent potliner and salt cake resulting from aluminium-dross recycling. Pradhan et al. [2] developed a process for production of superfine white aluminium trihydroxide powders from actual plant Bayer liquor. Barakat et al. [3] removed aluminum and regenerated caustic soda from the spent washing liquor of aluminium etching using lime neutralization processes. Gürel et al. [4] produced fine reactive alumina powder using Bayer gibbsite as a starting material.

Alumina is a strong adsorber and can function as an amphoteric ion exchanger depending on the nature of the surface and the solvent [5]. It is also used alone or impregnated with promotes as a catalyst. By changing variables such as the degree of crystallinity, the purity, the activation temperature and the rate of heating, a wide variety of materials can be made to meet special needs [6]. Ceramic industry processes alumina by grinding, adding other materials to form vitreous bonds, forming by any of several processes and firing [7]. Alumina is also used in electronic circuits or can be fused to form blocks used in lining glass furnaces [8]. It can be also used as an adsorbent for purification or treatment of radioactive and industrial waste solutions.

\section{Experimental materials, methods and analysis}

\subsection{Materials}

Samples from the solid waste obtained as a by-product from some factories that produce kitchen utensils were collected for characterization and for the leaching process. Sodium hydroxide of commercial grade and tap water were used in the leaching process.

\subsection{Characterization of the solid waste}

Solid sample is a brownish white powder. When fractionized by sieving it showed that it contains $84 \%$ by weight of particle size between 53 to $75 \mu \mathrm{m}$, while it contains $16 \%$ of particle size between 150 to $300 \mu \mathrm{m}$. Analysis of the solid waste under investigation using the XRF is given in table 1 .

\subsection{Leaching procedure}

Different concentrations of sodium hydroxide solutions were tested for leaching the solid waste containing aluminum species $(10,20,30$ and $40 \%)$.Different solid to solution ratios $(1: 1,1: 2,1: 3$ and 1:4) were also tested for the leaching process. The following is the standard procedure, unless otherwise stated:

A $100 \mathrm{~g}$ representative sample of the solid waste was added into a $1 \mathrm{~L}$ capacity of Pyrex beaker. Sodium hydroxide solution was transferred to the beaker. The 
resulting slurry was heated for different defined periods, and a magnetic rod was used for stirring. The liquor obtained, which is mainly sodium aluminate was then filtered.

\subsection{Precipitation procedure}

Aluminum ions leached in the hot filtrate was precipitated by bubbling $\mathrm{CO}_{2}$ gas $(7 \mathrm{~L} / \mathrm{min})$ for certain time through the solution till complete precipitation $(\mathrm{pH} 7)$. The precipitate formed, $\mathrm{Al}(\mathrm{OH})_{3}$ was then separated by filtration through Whatman filter paper No. I. The precipitate was washed with tap water and dried in an oven at $100^{\circ} \mathrm{C}$ till constant weight to remove free water. The dried precipitate was subjected to calcination at $600^{\circ} \mathrm{C}$ and $1000^{\circ} \mathrm{C}$ for 5 hours to produce $\mathrm{Al}_{2} \mathrm{O}_{3}$ (alumina) in $\gamma$ - or $\alpha$-forms, respectively .

Table 1: Characterization of the solid waste.

\begin{tabular}{ll}
\hline Elements & Concentration $(\%)$ \\
\hline $\mathrm{Al}$ & 90.27 \\
$\mathrm{Mg}$ & 0.92 \\
$\mathrm{Si}$ & 0.39 \\
$\mathrm{Ca}$ & 0.41 \\
$\mathrm{Fe}$ & 0.26 \\
$\mathrm{Na}$ & 2.71 \\
$\mathrm{Ti}$ & 0.014 \\
$\mathrm{~K}$ & 0.026 \\
L.O.I & 2.92 \\
\hline
\end{tabular}

\subsection{Analysis and measurements}

Solid samples were analyzed using XRF, DTA of type DTA/DSC, the crystalline phase and microstructure were characterized using SEM, and XRD of type Bruker Axs-D8 Advance. The particle size distribution was determined by a laser scattering technique (Quanta chrome NOVA Automated Gas Sorption System) and analytical Sieve (Fritsch). The optical properties were determined using the whiteness instrument.

\section{Results and discussion}

\subsection{Leaching process}

To recover aluminum ions in solution from the solid waste, a leaching process was carried out using $\mathrm{NaOH}$ solution. The different parameters affecting the leaching process were studied. 


\subsubsection{Effect of $\mathrm{NaOH}$ concentration}

The effect of $\mathrm{NaOH}$ concentration on leaching $100 \mathrm{~g}$ of the solid waste was studied with four different concentrations $(10 \%, 20 \%, 30 \%$, and $40 \%)$, while the leaching time is kept constant (4 hours) for (1:2) solid to liquid ratio. It was found that as $\mathrm{NaOH}$ concentration increases the amount of dissolved waste increases as shown in table 2 .

\subsubsection{Effect of solid to solution ratio}

The effect of solid to solution ratio on leaching of $100 \mathrm{~g}$ solid waste was studied with four different ratios $(1: 1,1: 2,1: 3$, and 1:4). The leaching time is kept constant (4 hours) and the concentration of $\mathrm{NaOH}$ was $30 \%$. It was found that the amount of dissolved waste increases with increase in the ratios shown in table 3 .

Table 2: Effect of $\mathrm{NaOH}$ concentration.

\begin{tabular}{lll}
\hline $\begin{array}{l}\mathrm{NaOH} \\
\text { concentration }\end{array}$ & $\begin{array}{l}\text { Amount of sludge } \\
\text { remained(g) }\end{array}$ & leaching \% \\
\hline $10 \%$ & $80.4 \mathrm{~g}$ & $19.6 \%$ \\
$20 \%$ & $42.0 \mathrm{~g}$ & $58.0 \%$ \\
$30 \%$ & $12.0 \mathrm{~g}$ & $88.0 \%$ \\
$40 \%$ & $10.0 \mathrm{~g}$ & $90.0 \%$ \\
\hline
\end{tabular}

Table 3: Effect of solid to solution ratio.

\begin{tabular}{lll}
\hline $\begin{array}{l}\text { Solid solution } \\
\text { ratio }\end{array}$ & $\begin{array}{l}\text { Amount of sludge } \\
\text { remained(g) }\end{array}$ & leaching \% \\
\hline $1: 1$ & $16.2 \mathrm{~g}$ & $83.8 \%$ \\
$1: 2$ & $12.0 \mathrm{~g}$ & $88.0 \%$ \\
$1: 3$ & $10.7 \mathrm{~g}$ & $89.3 \%$ \\
$1: 4$ & $9.0 \mathrm{~g}$ & $91.0 \%$ \\
\hline
\end{tabular}

\subsubsection{Effect of time}

The effect of time on leaching the solid waste was studied with five different time intervals (1, 2, 3, 4 and 6 hours), while the $\mathrm{NaOH}$ concentration is kept constant at $30 \%$ for $1: 2$ solid to liquid ratio. It is clear that as leaching time increases the amount of dissolved waste increases as shown in table 4 .

Table 4: Effect of time.

\begin{tabular}{lll}
\hline Time & $\begin{array}{l}\text { Amount of sludge } \\
\text { remained(g) }\end{array}$ & leaching \% \\
\hline $1 \mathrm{~h}$. & $25.0 \mathrm{~g}$ & $75.0 \%$ \\
$2 \mathrm{~h}$. & $17.1 \mathrm{~g}$ & $86.9 \%$ \\
$3 \mathrm{~h}$. & $15.7 \mathrm{~g}$ & $87.3 \%$ \\
$4 \mathrm{~h}$. & $22.0 \mathrm{~g}$ & $88.0 \%$ \\
$6 \mathrm{~h}$. & $10.1 \mathrm{~g}$ & $89.9 \%$ \\
\hline
\end{tabular}




\subsubsection{Effect of temperature}

The effect of solution temperature on leaching the solid waste was studied with four different temperatures $\left(70^{\circ} \mathrm{C}, 80^{\circ} \mathrm{C}, 90^{\circ} \mathrm{C}\right.$ and $\left.100^{\circ} \mathrm{C}\right)$, while the leaching time is kept constant (4 hours) for (1:2) solid to liquid ratio and for $30 \% \mathrm{NaOH}$ concentration. By increasing the temperature the amount of dissolved waste increases as shown in table 5 .

Table 5: Effect of temperature.

\begin{tabular}{lll}
\hline Temperature & $\begin{array}{l}\text { Amount of sludge } \\
\text { remained(g) }\end{array}$ & leaching \% \\
\hline $70^{\circ} \mathrm{C}$ & $27.2 \mathrm{~g}$ & $72.8 \%$ \\
$80^{\circ} \mathrm{C}$ & $17.0 \mathrm{~g}$ & $83.0 \%$ \\
$90^{\circ} \mathrm{C}$ & $15.0 \mathrm{~g}$ & $85.0 \%$ \\
$100 \mathrm{oC}$ & $12.0 \mathrm{~g}$ & $88.0 \%$ \\
\hline
\end{tabular}

It is clear from the obtained results in Tables 2-5 that increasing the concentration of $\mathrm{NaOH}$ solution from $30 \%$ to $40 \%$ shows no significant increase in the leaching process (Table 2), therefore, for economical purposes, $30 \%$ of the $\mathrm{NaOH}$ solution was found enough for the leaching process. For the same purpose, the solid to solution ratio of 1:4 was found to be suitable (Table 3). In addition, to avoid time consumption, leaching time for 2 hours was found enough for the leaching process at $100^{\circ} \mathrm{C}$ (Tables 4,5 ).

\subsection{Precipitation process}

Aluminum ions leached in the alkaline solution namely as sodium aluminate $(\mathrm{pH} 14)$ were precipitated as aluminum hydroxide by lowering the $\mathrm{pH}$ of the leached solution to 7 . This was done by bubbling $\mathrm{CO}_{2}$ gas $(7 \mathrm{~L} / \mathrm{min})$ for a certain time through the hot solution till complete precipitation; the precipitate was washed by hot water to dissolve any precipitated $\mathrm{Na}_{2} \mathrm{CO}_{3}$.

\subsection{Calcination of alumina}

The produced precipitate of aluminum hydroxide was first dried at $100^{\circ} \mathrm{C}$ in an oven to eliminate free water. The dried product was calcined at $600^{\circ} \mathrm{C}$ or $1000^{\circ} \mathrm{C}$ for 5 hours to produce $\mathrm{Al}_{2} \mathrm{O}_{3}$ (alumina) in $\gamma$ - or $\alpha$ - forms, respectively. $\gamma$ - form of alumina is used as an adsorbent for separation processes.

\subsection{Characterization of alumina}

Table 6 represents the data obtained from the different analyses on the produced alumina. The peaks of the XRD patterns for the recovered alumina coincided with that of (semi-crystalline) pattern of $\gamma$ - alumina as shown in Fig. 2. The thermal behavior of $\gamma$ - alumina was investigated (Fig. 3), in the DTA curve, three endothermic peaks were observed at temperatures in the range $100-300^{\circ} \mathrm{C}$ were considered to be due to dehydration [9]. 
The specific surface area $\left(\mathrm{S}_{\mathrm{BET}}\right)$ of $\gamma$ - alumina is $140 \mathrm{~m}^{2} / \mathrm{g}$, which is relatively high compared to those reported [9].

Table 6: Characterization of alumina.

\begin{tabular}{|c|c|}
\hline \multicolumn{2}{|c|}{ Aluminium oxide } \\
\hline Names & Anhydrous aluminium oxide, $\gamma$ - alumina \\
\hline $\begin{array}{l}\text { Chemical } \\
\text { formula }\end{array}$ & $\mathrm{Al}_{2} \mathrm{O}_{3}$ \\
\hline Chemical & $\mathrm{Al}_{2} \mathrm{O}_{3}-97.8 \%$ \\
\hline composition & $\mathrm{MgO}-0.18$ \\
\hline$(\mathrm{XRF})$ & $\mathrm{SiO}_{2}-0.57$ \\
\hline & $\mathrm{CaO}-0.028$ \\
\hline & $\mathrm{Fe}_{2} \mathrm{O}_{3}-0.035$ \\
\hline & $\mathrm{TiO}_{2}-0.011$ \\
\hline & L.O.I -0.67 \\
\hline
\end{tabular}

$\underline{\text { Physical properties }}$

$\begin{array}{ll}\text { Apparent } & 0.3 \mathrm{~g} / \mathrm{cm}^{3} \\ \text { Density } & \\ \text { Melting point } & 2015-2072^{0} \mathrm{C} \\ \begin{array}{l}\text { Maximum } \\ \text { temperature of } \\ \text { use }\end{array} & 1600^{\circ} \mathrm{C} \\ \end{array}$

$\underline{\text { Chemical properties }}$

$\begin{array}{ll}\begin{array}{l}\text { Moisture } \\ \text { content } \\ \text { pH of water } \\ \text { suspension }\end{array} & 4-5 \% \\ & \end{array}$

Optical properties

$\begin{array}{ll}\text { Color } & \text { White } \\ \text { Whiteness } & 98.01 \% \\ \text { Brightness } & 93.83 \% \\ \text { Iso-brightness } & 96.07 \%\end{array}$

Morphology

Particle shape Irregular (as shown in fig. 1)

by(SEM)

Pore diameter $\quad 1.947 \mathrm{E}+01 \mathrm{~A}^{0}$

Pore volume $\quad 0.1280 \mathrm{cc} / \mathrm{g}$ 
Table 6: Continued.

\begin{tabular}{ll}
\hline Morphology & \\
Sieve analysis & $28.00 \%$ on $850 \mu \mathrm{m}$ sieve \\
& $11.40 \%$ on $600 \mu \mathrm{m}$ sieve \\
& $11.56 \%$ on $280 \mu \mathrm{m}$ sieve \\
& $10.29 \%$ on $420 \mu \mathrm{m}$ sieve \\
& $12.91 \%$ on $212 \mu \mathrm{m}$ sieve \\
& $14.14 \%$ on $180 \mu \mathrm{m}$ sieve \\
& $9.06 \%$ on $152 \mu \mathrm{m}$ sieve \\
& $8.98 \%$ on $125 \mu \mathrm{m}$ sieve \\
& $2.73 \%$ on $106 \mu \mathrm{m}$ sieve \\
& $0.75 \%$ on $63 \mu \mathrm{m}$ sieve \\
& $0.15 \%$ on $45 \mu \mathrm{m}$ sieve \\
& $0.18 \%$ on $<45 \mu \mathrm{m}$ sieve \\
& \\
Specific surface & $139.07 \pm 1.944 \mathrm{~m}^{2} / \mathrm{g}$ \\
area & \\
\hline
\end{tabular}

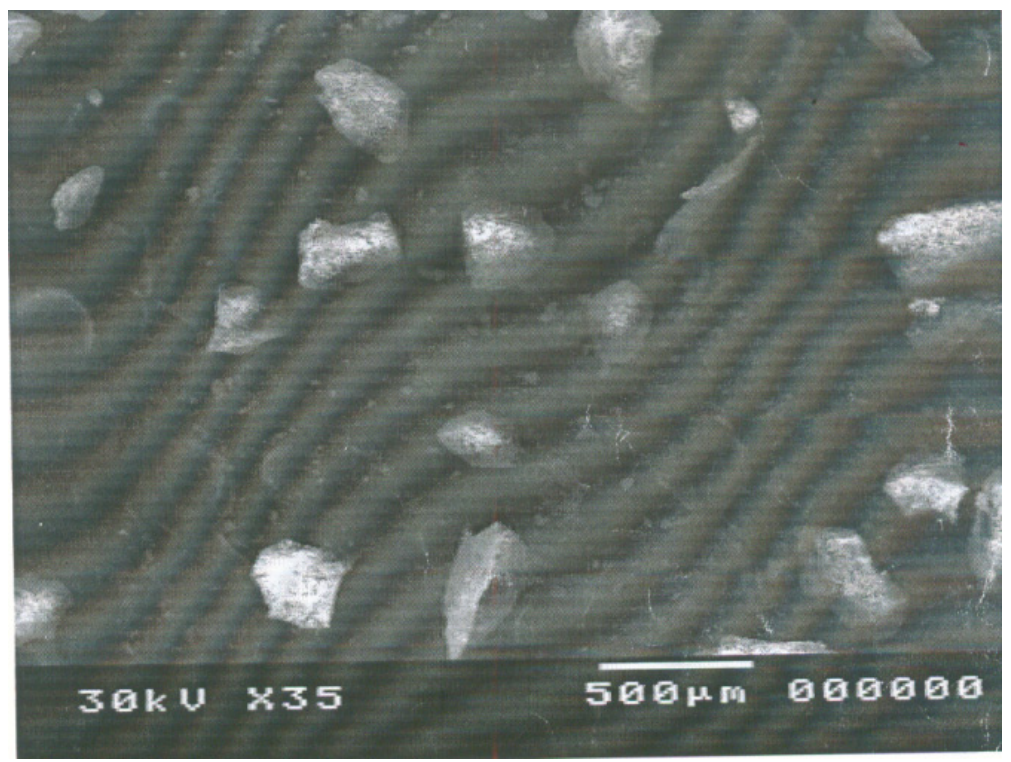

Figure 1: SEM micrograph for alumina particles. 


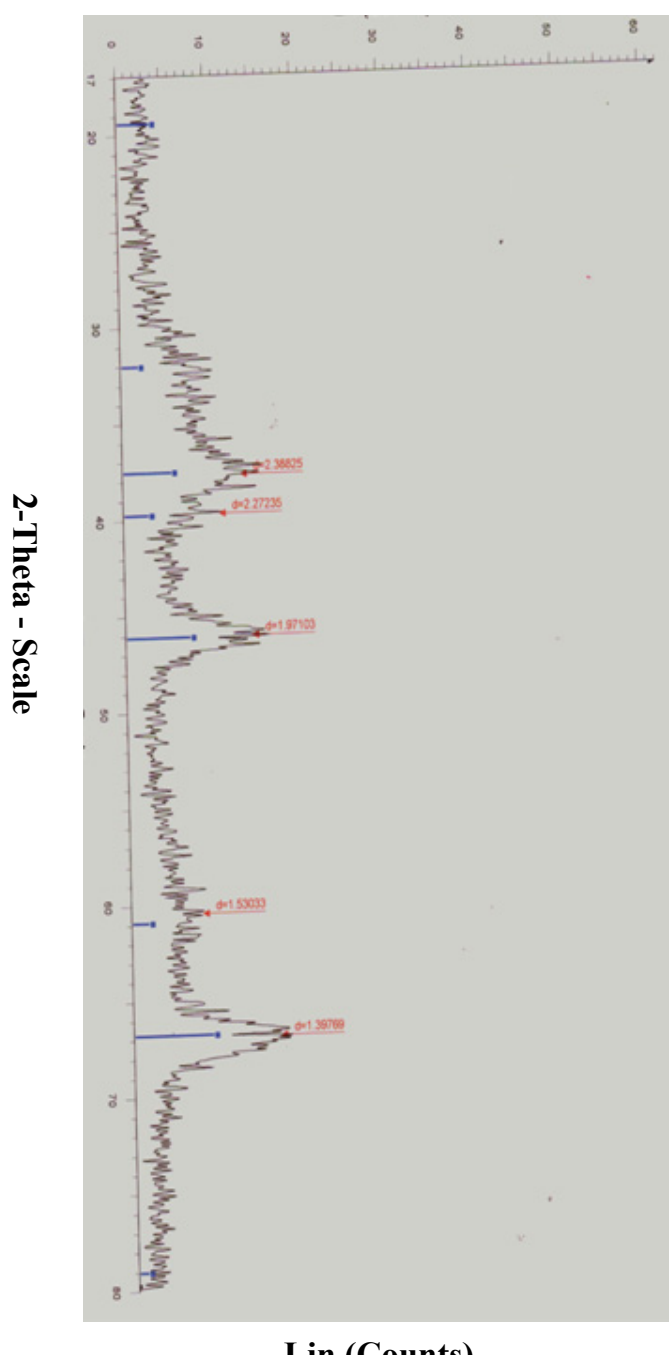

\section{Lin (Counts)}

Figure 2: XRD pattern for alumina.

IR patterns for both the solid waste and the recovered alumina are given in Fig. 4 (1) and (2), there are nine IR peaks in the waste (559.1, 800.0, 1028.1, $1419.5,1559.5,1653.9,2016.5,2360.8$, and $\left.3526.1 \mathrm{~cm}^{-1}\right)$ due to organic substances from the lubricants. But for $\gamma$-alumina the pattern shows only one peak $\left(746.5 \mathrm{~cm}^{-1}\right)$ due to $\mathrm{Al}-\mathrm{O}$ bond as in Fig. 4 . 


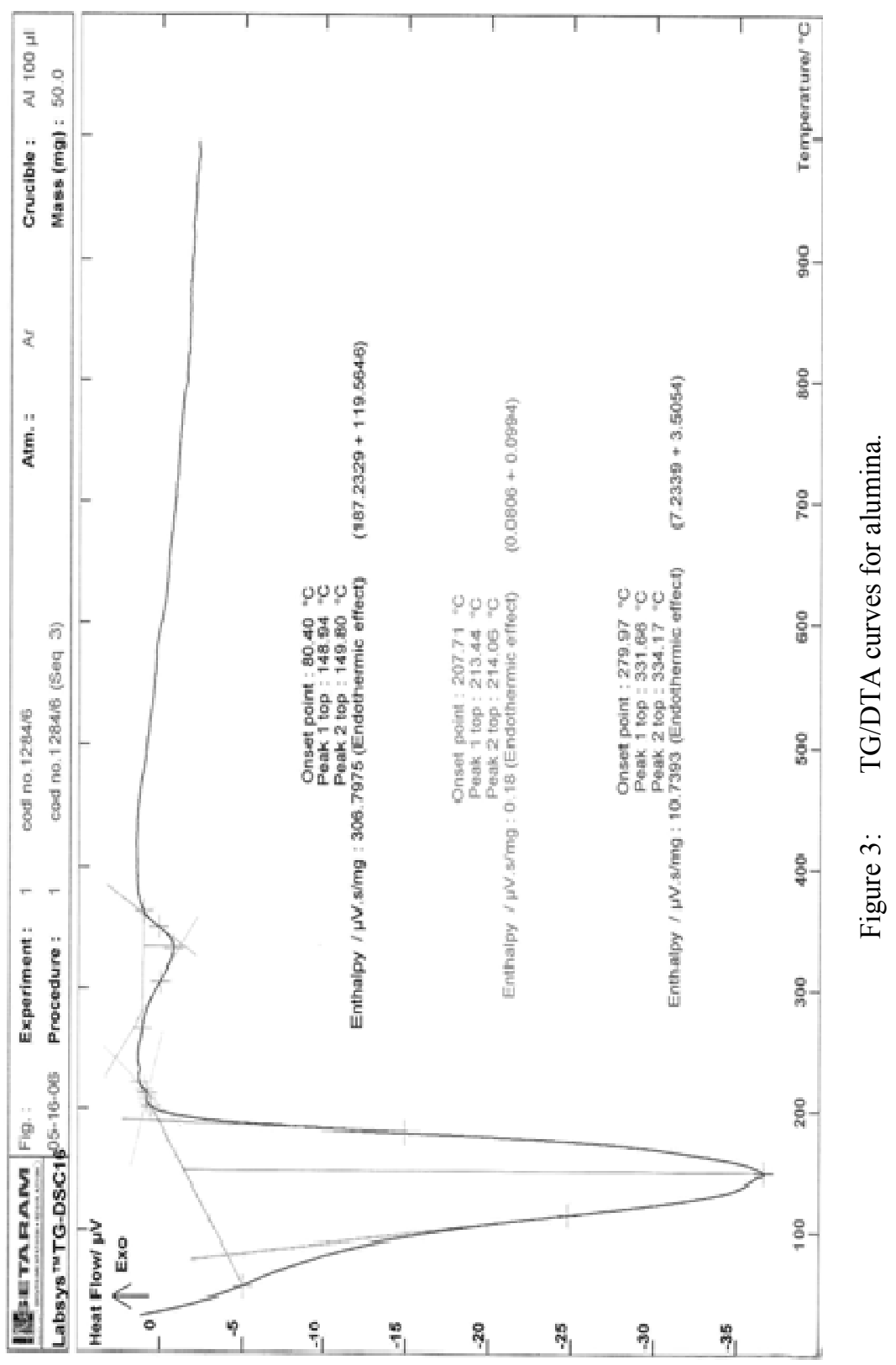



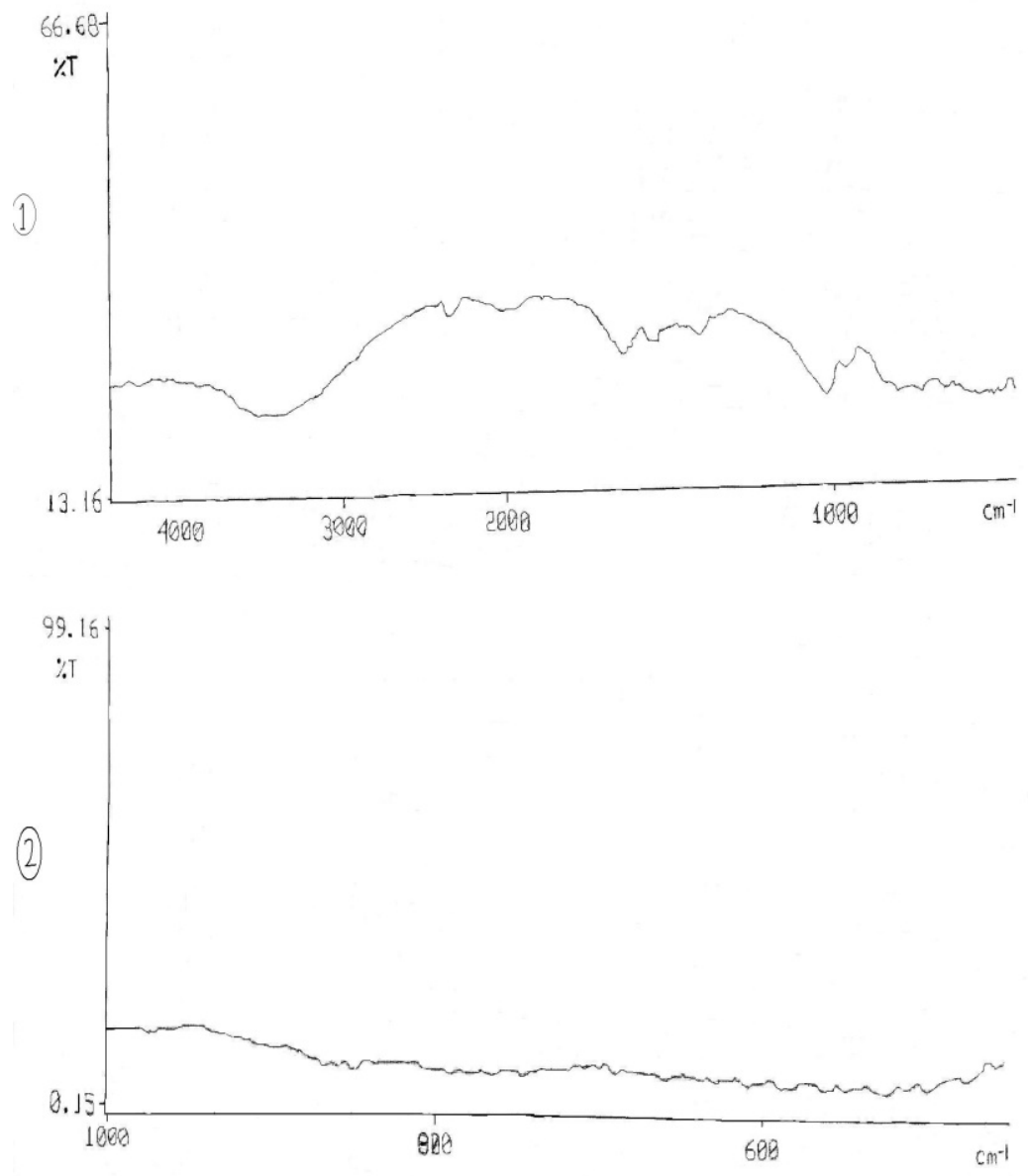

Figure 4: IR patterns for (1) the waste and (2) $\gamma$-alumina.

\section{Conclusions}

In conclusion, it was found that, under the suitable conditions investigated, about $88 \%$ of pure alumina $(97.8 \%)$ can be recovered from the solid waste obtained as a by-product from some aluminum small factories. Fig. 5 illustrates a recommended flow sheet for the whole recycling process required for the production of alumina from the solid waste under investigation. The future work will be done on the uses of alumina as an effective adsorbent for treatment of both industrial and radioactive waste solutions. 


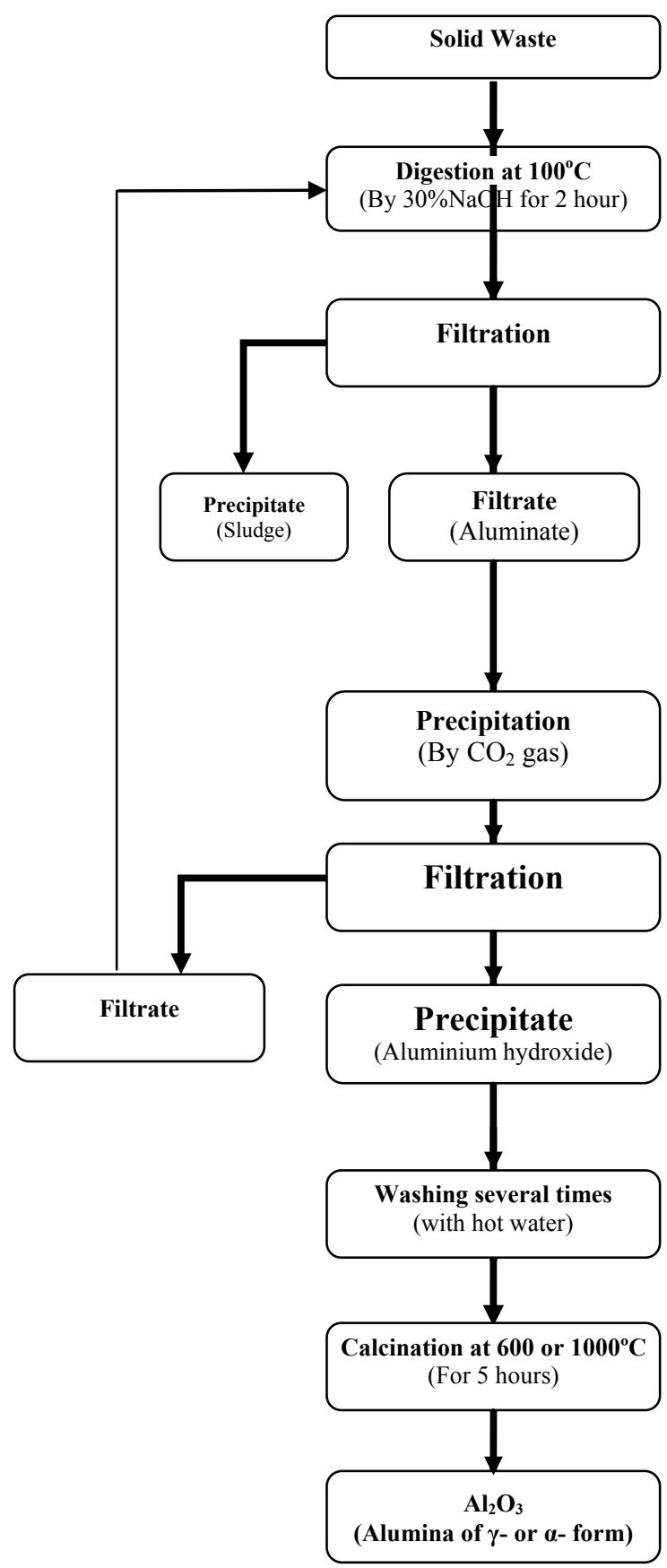

Figure 5: Flow sheet of the recycling process for producing alumina from the solid waste. 


\section{Acknowledgements}

The authors are deeply grateful to Prof. Dr. Ragaie Zaghloul, Hot Lab. Center, Atomic Energy Authority for providing the waste. Thanks are also due to Prof. Dr. Hisham Aly, Hot Laboratories Center, Atomic Energy Authority, for his fruitful discussions.

\section{References}

[1] Rayzman, V., Filipovich, I., Nisse, L. \& Vlasenko, Y., Sodium aluminate from alumina-bearing intermediates and wastes, JOM; ProQuest Science Journals, 50, 11: 32 (1998).

[2] Pradhan, J. K., Gochhayat, P. K., Bhattacharya, I. N. \& Das, S. C., Study on the various factors affecting the quality of precipitated non-metallurgical alumina trihydrate particles, Hydrometallurgy 143, 60 (2001).

[3] Barakat, M. A., El-Sheikh, S. M. \& Farghaly, F. E., Removing Al and regenerating caustic soda from the spent washing liquor of Al etching ,JOM; ProQuest Science Journals. 57, 8: 34 (Aug. 2005).

[4] Gürel, S. B. \& Altun, A., Reactive alumina production for the refractory industry, Powder Technology 196, 115: 121 (2009).

[5] Braithwaite, A. \& Smith, F. G., "Chromatographic Methods", Fourth Ed., London, N. Y. Chapman \& Hall, by M. W. Arrowsmith Ltd, (1985).

[6] Keith Hudson, L., Critical report on applied chemistry, Imperial College, London vol. 20 (1987).

[7] Fereira, L. E.; Briggs, D. D.; Barnhart, R.G., Engineering with high-alumina ceramics. Metal Progr. 98, 78 (1970).

[8] Dorre, E. \& Hubner, H., "Alumina processing, properties, and applications" New York, 1984.

[9] Park, H. C., Synthesis of alumina from high purity alum derived from coal fly ash, Materials Science and Engineering A367, 166 (2004). 